\title{
ERRATUM
}

\section{An Integrated Approach to the Pharmacokinetic Analysis of Drug Absorption}

\author{
Alice E. Till, Leslie Z. Benet, and K. C. Kwan
}

In this report (Vol. 2, No. 6, 1974, pp. 525-544), equation 23 on p. 537 was incorrectly stated. The equation should read

$$
\begin{aligned}
C_{T(t=n)}= & C_{T(t=n-1)} e^{-k_{21} \Delta t} \\
& +\frac{k_{12} \Delta t}{k_{21} \Delta t-\ln \left[C_{p(t=n-1)} / C_{p(t=n)]}\right]}\left[C_{p(t=n)}-C_{p(t=n-1)} e^{-k_{21} \Delta t}\right]
\end{aligned}
$$

Since it is impossible to use equation 23 during the first time increment where $C_{p(t=n-1)}=0$, the nonlogarithmic form of the Loo-Riegelman treatment (2) should be used. Equation 23 has previously been described by Loo (13) but is not readily available to the general reader.

\section{REFERENCES}

2. J. C. K. Loo and S. Riegelman. New method for calculating the intrinsic absorption rate of drugs. J. Pharm. Sci. 57:918-928 (1968).

13. J. C. K. Loo. Pharmacokinetic methods of assessing drug absorption: Evaluation and the application of kinetic methods in the investigation of bioavailability of solid oral dosage forms. Thesis, University of California, San Francisco, 1971, pp. 15-18. 